Dr. Eduardo Fernández

Dra. Camila Alvarado
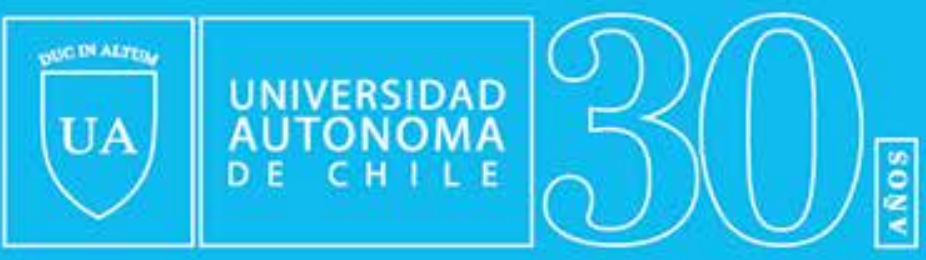



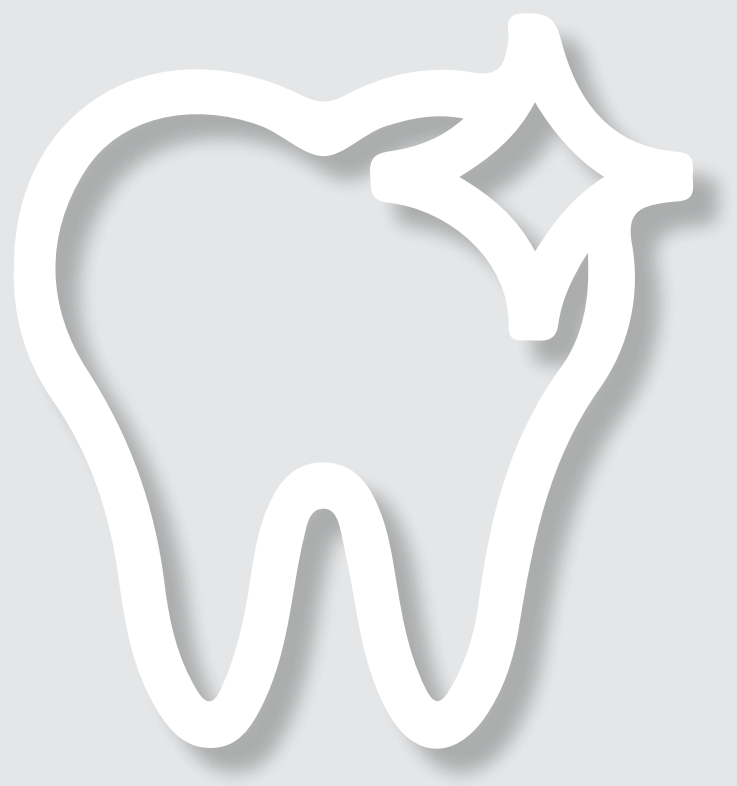




\section{¿CUÁNDO DEBO IR AL DENTISTA?}

Primera edición. Abril, 2019

Santiago, Chile.

CUniversidad Autónoma de Chile. Centro de Comunicación de las Ciencias

http://ciencias.uautonoma.cl

\section{Autores:}

Dr. Eduardo Fernández

y Dra. Camila Alvarado

Dirección editorial y corrección de textos:

Isidora Sesnic

Diseño y diagramación:

Claudio Alvarado

ISBN: 978-956-8454-31-9

Registro de propiedad intelectual: 301229

\section{(c) (i) (3) ()}

Este material puede ser distribuido, copiado y exhibido por terceros si se muestra en los créditos y solo para fines educacionales y de divulgación científica. No se puede obtener ningún beneficio comercial y las obras derivadas tienen que estar bajo los mismos términos de licencia que el trabajo original.
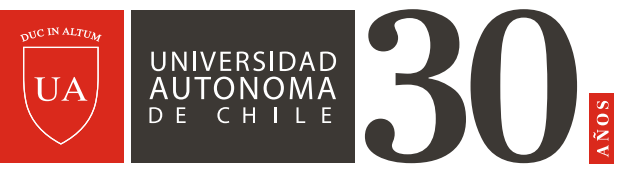


\title{
Introducción
}

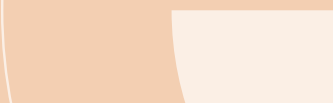

Capítulo 1

\section{DE ACUERDO CON MI EDAD}

Preescolares y escolares

Adultos

Adultos mayores

Capítulo 2

DE ACUERDO CON MI SITUACIÓN

DE SALUD GENERAL Y LA DE MI BOCA

Cuando tengo alguna condición oral previa

Cuando tengo alguna condición de salud general

Cuando estoy tomando ciertos medicamentos

Capítulo 3

\author{
DE ACUERDO CON MI RIESGO \\ Riesgo psicosocial \\ Riesgo biológico
}

Apéndice
AYUDA MEMORIA
GES Odontológico
¿Cuándo debo ir al dentista?

Bibliografía

Sobre los autores / Agradecimientos 


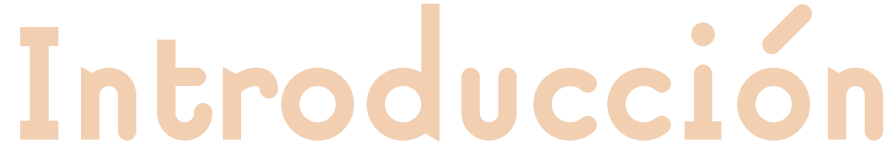

Las enfermedades bucales son las más comunes de las enfermedades crónicas y son un importante problema de salud pública por su alta prevalencia, el costo de su tratamiento y el impacto en los individuos. Según la Encuesta Nacional de Calidad de Vida (ENCAVI) realizada el año 2015 - 2016, un 28,1\% del total país considera que más de alguna vez el estado de sus dientes y encías ha afectado en su calidad de vida (1).

Las patologías bucales de mayor prevalencia son la caries dental, problemas periodontales y anomalías dentomaxilares. La caries dental es la principal causa de pérdida de dientes, ya que nueve de cada diez personas presentan la enfermedad o alguna secuela de esta. Debido a esto, ha sido necesario orientar las políticas de salud bucal hacia estrategias promocionales y preventivas enfocadas a los grupos más vulnerables y de alto riesgo, priorizando así a la población menor de 20 años (2).

En Chile, se observa una disminución de la enfermedad de caries en los últimos años. Esto se debe a que, por un lado, ha habido una mayor implementación de programas de prevención y promoción de salud bucal, y por otro, a la masificación del uso de fluoruros, ya que desde el año 1986 se ha implementado su incorporación en las aguas potables de Chile y, además, se ha puesto énfasis en el uso e importancia de las pastas dentales, dado que el flúor es su ingrediente activo y posee un efecto anticariogénico (3) (4).

Este libro está dirigido a toda la población, incluyendo a quienes no posean conocimiento previo del área odontológica y su propósito es entregar una orientación sobre salud oral basada en la evidencia científica disponible, para apoyar la toma de decisiones de la población y servir de guía para saber cuándo se debe acudir a un odontólogo, con el fin de que este pueda diagnosticar, prevenir y tratar condiciones y patologías orales de forma oportuna y precoz.

En ese contexto, este libro tiene por objetivos:

1. Entregar recomendaciones sobre cuándo acudir a un dentista.

2. Proporcionar información de GES (Garantías Explícitas en Salud) odontológico, patologías y condiciones orales, patologías sistémicas y medicamentos que afectan a la salud oral, entre otros. 


\section{De acuerdo con mi edad}

Teniendo en cuenta las diferentes edades de las personas, en este capítulo se abordan recomendaciones a las situaciones más frecuentes que podrían significar una consulta al dentista. 


\section{De acuerdo con mi edad}

\section{-) PREESCOLARES Y ESCOLARES}

Es importante crear buenos hábitos orales en los niños desde sus primeros años de vida, ya que la salud bucal es parte de la salud general y se relaciona directamente con el bienestar físico, la autoestima, la comunicación y las relaciones sociales.

Para cuidar la salud oral y prevenir la formación de caries, gingivitis y anomalías dentomaxilares en los dientes, encías y huesos que soportan los dientes, debemos enseñar a los niños hábitos de higiene bucal, buenas prácticas de alimentación y evitar malos hábitos como chuparse el dedo, morder objetos o comerse la uñas (5) (6).

En niños de hasta seis años se da una presentación agresiva de la enfermedad de caries llamada caries temprana de la infancia, donde existe la presencia de una o más superficies dentarias cariadas. En niños menores de tres años, cualquier signo (cavitación) o mancha en caras visibles (frontales y/o hacia el paladar o lengua) de los dientes, podría ser un signo de caries temprana de la infancia y, por lo mismo, es importante consultar oportunamente al dentista.

Con relación a la higiene bucal, a través del cepillado dental se logra remover la placa bacteriana, película incolora compuesta principalmente por bacterias y azúcares, que se adhiere a nuestros dientes y se encuentra en constante formación. Cuando no existe remoción de esta placa, las bac-

PREVALENCIA DE ENFERMEDADES ORALES (\%) ENTRE LOS AÑOS 2007-2010

\begin{tabular}{l|l|l|l}
\hline Edad & Caries & Gingivitis & Anomalías Dentomaxilares (ADM) \\
\hline 2 años & $17,5 \%$ & $32,6 \%$ & $48,8 \%$ \\
\hline 6 años & $70,4 \%$ & $55,1 \%$ & $38,3 \%$ \\
\hline 12 años & $62,5 \%$ & $66,9 \%$ & $53 \%$
\end{tabular}

*A los 12 años se observa una disminución del porcentaje de caries, esto se debe a que desde los seis hasta esa edad ocurre el recambio dentario en los niños. Una vez finalizado este recambio, la historia de caries comienza a aumentar nuevamente (7). 
terias dañinas producen ácidos que destruyen las capas externas de los dientes (esmalte dental) y se inflaman las encías, propiciando la aparición de lesiones de caries y gingivitis respectivamente (6).

Una alimentación saludable, alta en frutas y verduras, con un bajo consumo de grasas, sodio y azúcar (chocolates, galletas, bebidas gaseosas, etc.), permite cuidar la salud bucal. Además, se recomienda el consumo frecuente de agua potable, ya que al contener flúor protege a los dientes contra las caries (2).
Erupción dental (aparición de dientes) La erupción de la dentición primaria (dientes temporales o "de leche") ocurre entre los seis y 30 meses de vida aproximadamente. El total de dientes primarios son 20 (10 superiores y 10 inferiores). Los dientes primarios son tan importantes como los secundarios, pues sirven para masticar los alimentos, hablar correctamente y mantener el espacio para la dentición secundaria (dientes definitivos) (8).

Cuando los bebés presentan molestias durante la erupción dentaria, se pueden utilizar mordedores con gel frío, correctamente higienizados, o cubitos congelados de leche materna para aliviar la inflamación (8).
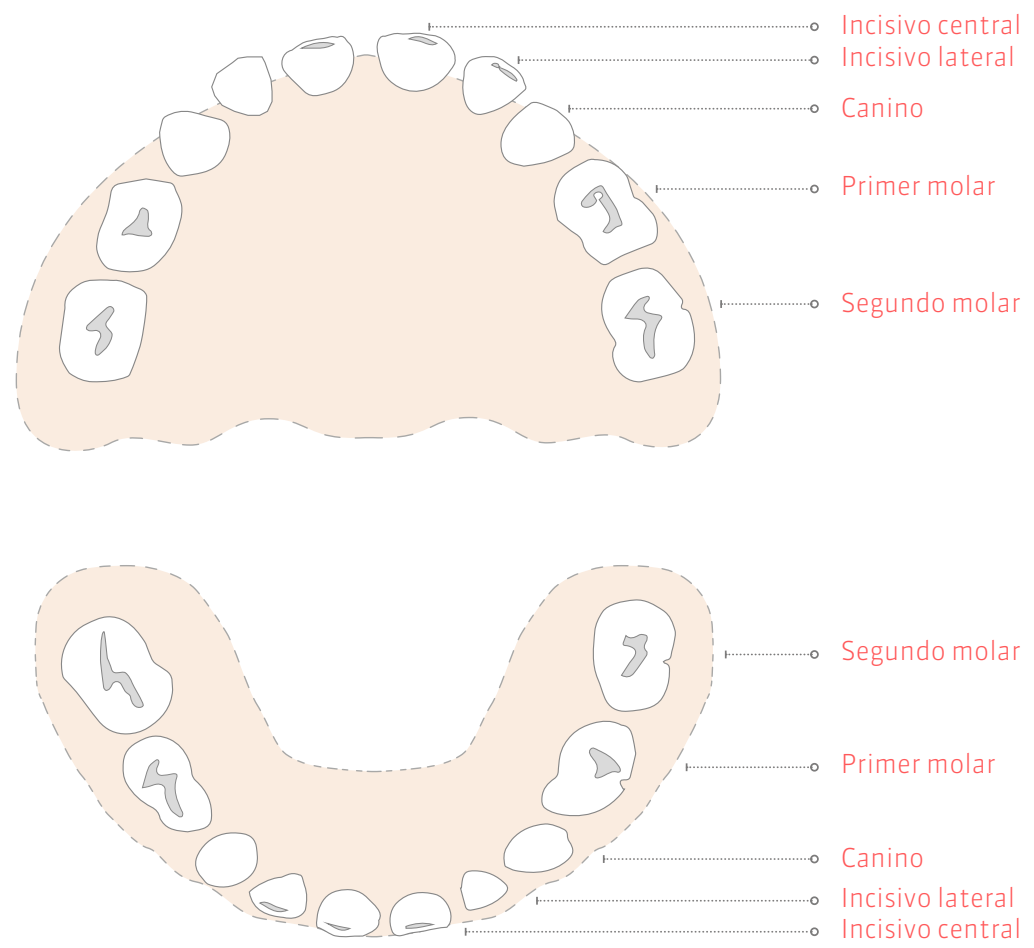
La dentición secundaria (dientes definitivos) se inicia a los seis años aproximadamente, con la erupción del primer molar, que aparece por detrás de los molares primarios. Este molar tiene un rol relevante en ajustar y estabilizar la oclusión o mordida en altura, ayudando a la correcta ubicación de los dientes. Generalmente, el recambio dentario finaliza a los 12 años. El total de dientes secundarios son 32 (16 superiores y 16 inferiores), ya que se incluyen los terceros molares ("muelas del juicio") que, en caso de erupcionar, lo harían entre los 17 y 21 años (8).

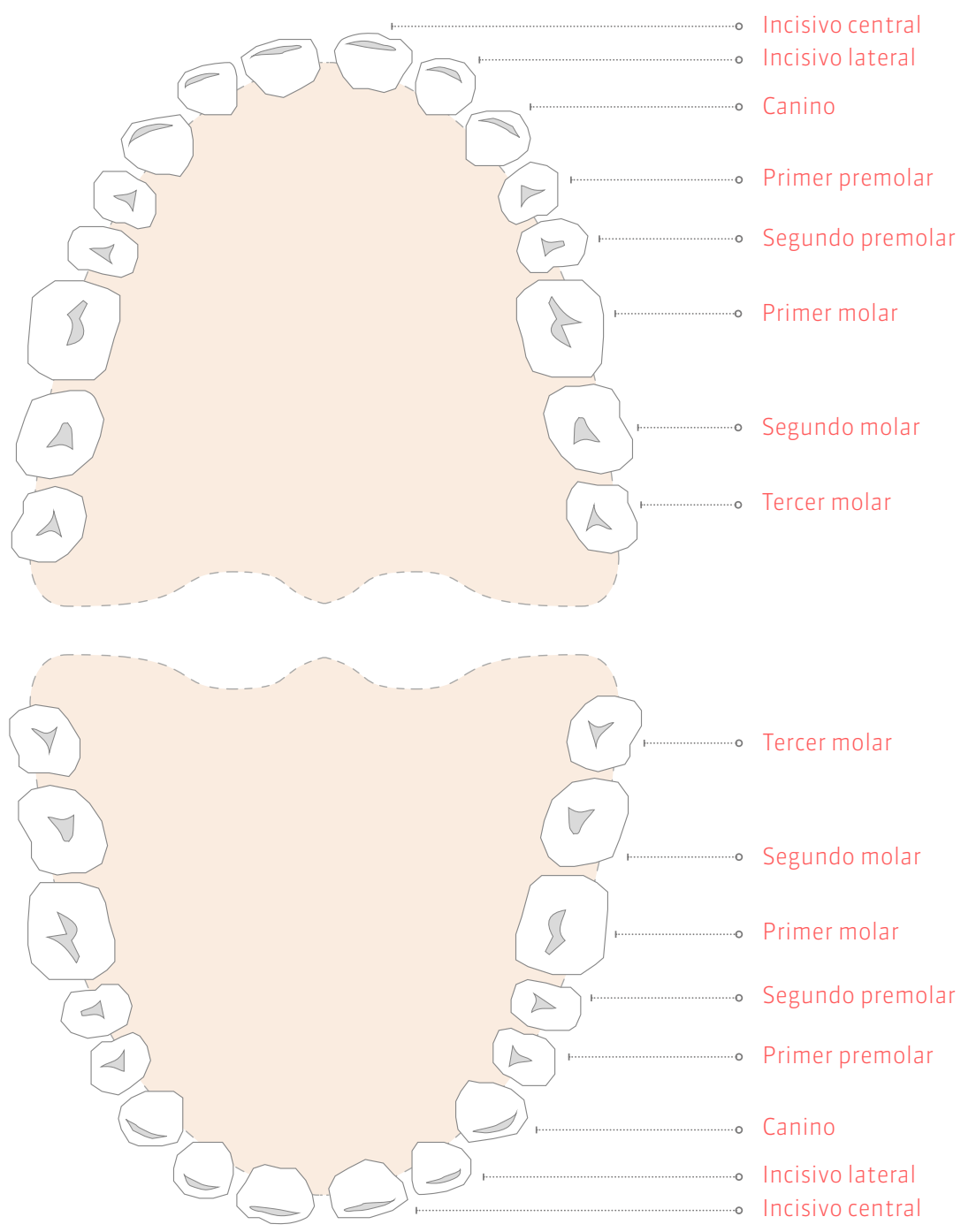




\section{Malos hábitos}

Un hábito es una práctica adquirida por la repetición frecuente de un mismo acto. Los malos hábitos pueden alterar el correcto desarrollo facial (cara), produciendo deformaciones en el sistema dentario y esqueletal; además, pueden causar daños psicológicos, emocionales, de fonación (habla), respiratorios y digestivos. El grado de alteración dependerá de la duración, intensidad y frecuencia del mal hábito, así como de las características faciales de cada paciente.

\section{MALOS HÁBITOS}

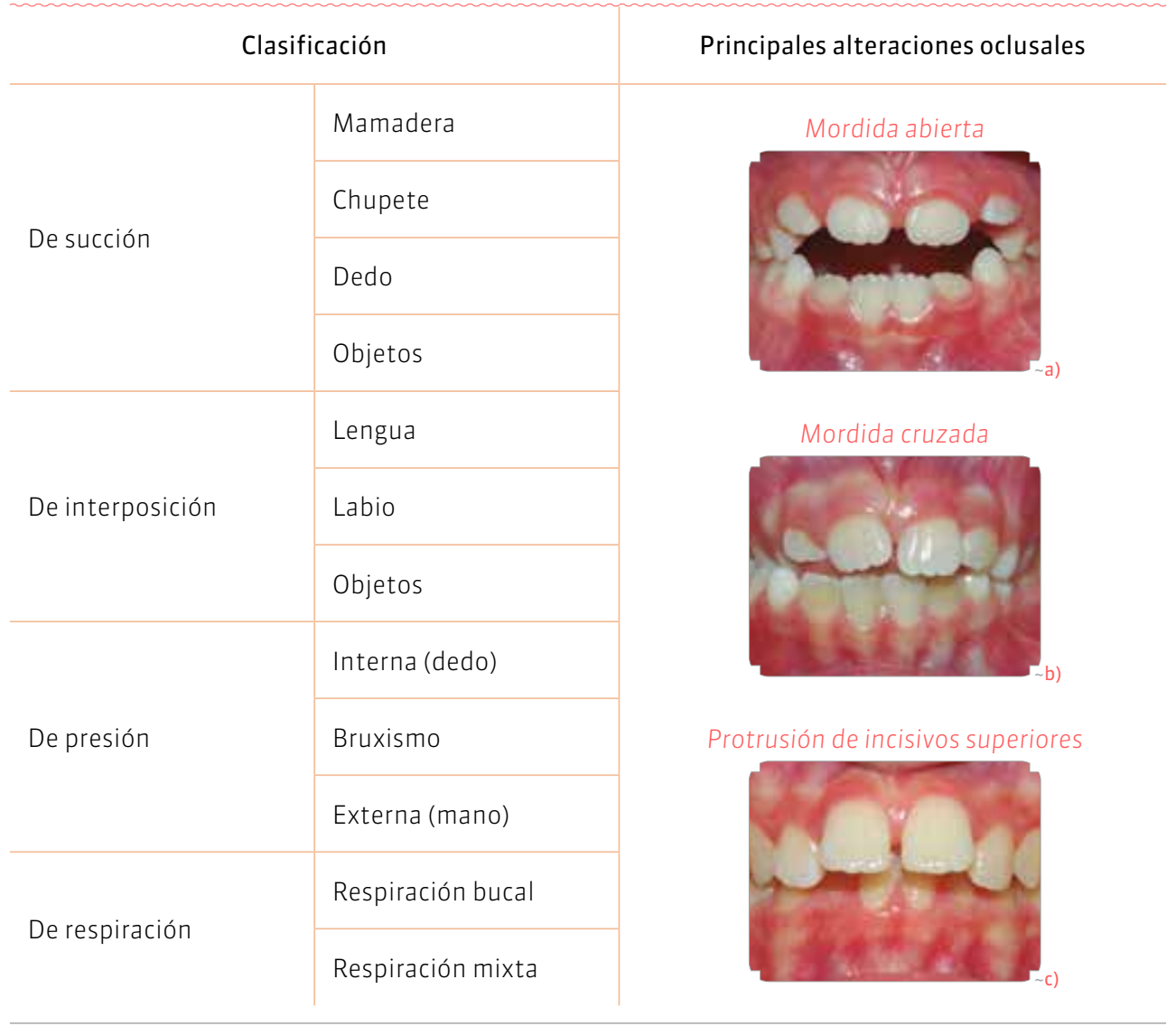

(9)

Es de gran importancia evitar estos malos hábitos, procurando que no se prolonguen más allá de los dos años, ya que estos se pueden corregir solo si se eliminan a tiem- po. Los padres deben realizar un trabajo de acompañamiento con los niños y usar incentivos y refuerzos positivos para que ellos adquieran buenos hábitos orales (9). 
Higiene oral

Cuando somos pequeños, nuestros padres son los encargados de incentivar, propiciar y mantener una correcta salud bucal; la principal herramienta que tienen estos frente a las enfermedades bucales, como la caries y la gingivitis, es una correcta higiene oral.

En un recién nacido, los padres deben limpiar las mejillas, lengua y paladar desde su primer día de vida. Esto se realiza con una gasa humedecida en agua tibia, por lo menos dos veces al día.

Para preescolares, desde la aparición del primer diente primario, hasta los siete años aproximadamente, se recomienda a los padres realizar la "Técnica circular", que consiste en:

1. Pedirle al niño o niña que junte sus dientes y realizar con el cepillo movimientos circulares amplios, como ruedas de bicicleta, desde el borde de la encía del diente superior al inferior, pasando por todos los dientes de derecha a izquierda.

2. Cepillar la cara interna de los dientes posteriores, haciendo círculos pequeños.

\section{Cepillar barriendo la cara interna de los dientes anteriores.}

4. En los molares o muelitas, realizar movimientos de arrastre, de atrás hacia adelante, en la superficie con que

\section{se mastica.}

5. Cepillar la lengua, de atrás hacia adelante, con suaves movimientos de arrastre (10).

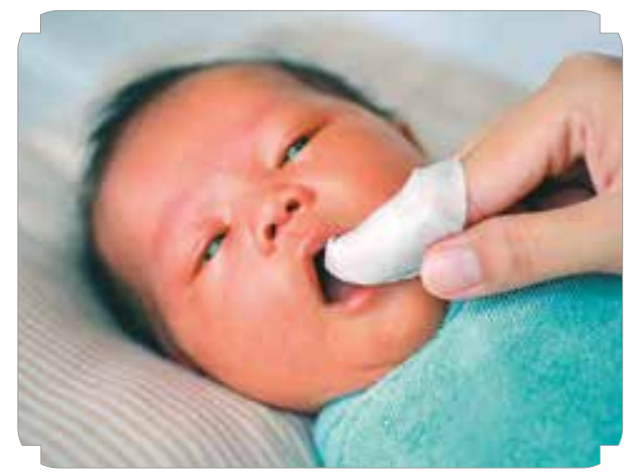


El cepillado debe ser realizado por un adulto hasta que el niño pueda realizarlo por sí mismo, y debe durar al menos dos minutos ya que, a mayor duración del cepillado, mayor remoción de placa bacteriana. La pasta dental debe ser utilizada en cantidades adecuadas para cada edad. Los padres deben cautelar que el niño no se trague la pasta, esto por riesgo de problemas gastrointestinales (10).

Para los escolares, que poseen una destreza motora adecuada, se pueden utilizar distintas técnicas de cepillado. Una de las técnicas más recomendadas y fáciles de realizar es la "Técnica de Bass modificada" (detallada en la página 12).

\section{¿QUÉ PASTA DENTAL DEBO USAR \\ Y CUÁNTO DEBO COLOCAR EN EL CEPILLO DENTAL?}

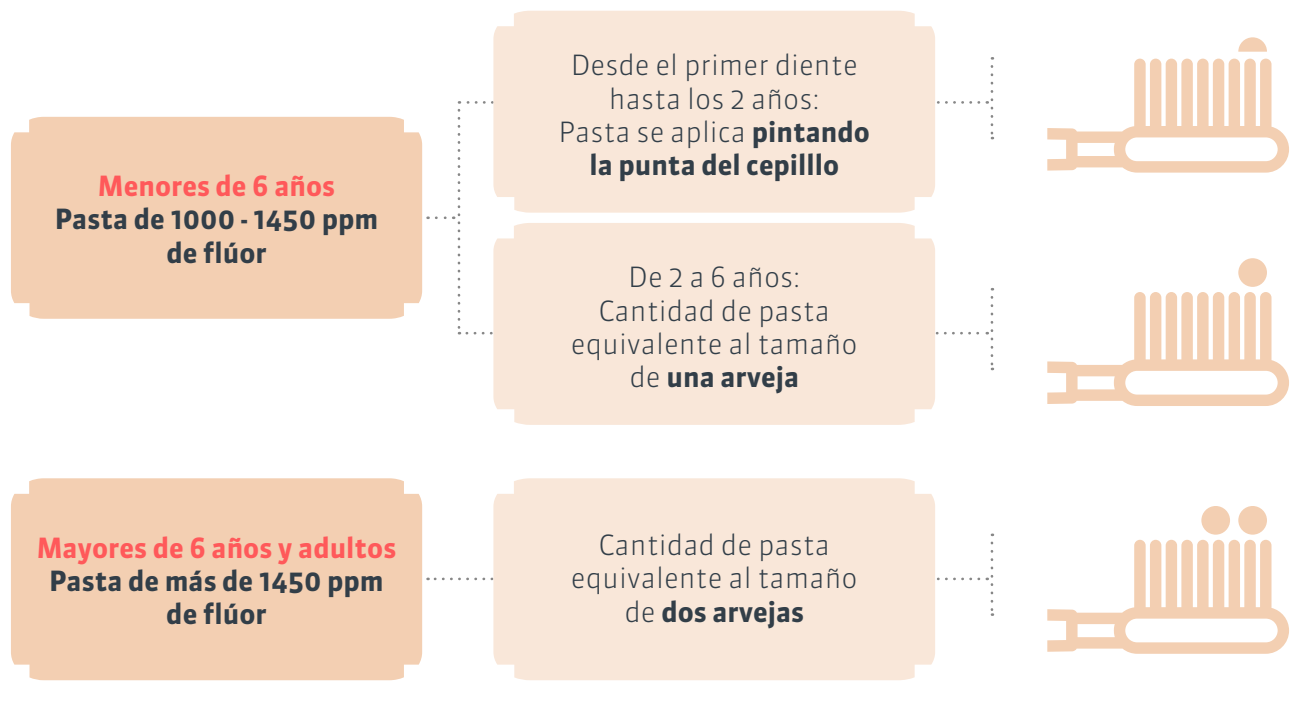

(11) 


\section{•> ADULTOS}

Las enfermedades bucales más comunes de los adultos son la caries dental y la enfermedad periodontal (enfermedad de las encías y de los tejidos que soportan el diente, entre estos, el hueso que rodea los dientes), teniendo como consecuencia, en muchos casos, la pérdida de piezas dentales. Estas enfermedades se asocian a una pobre higiene oral, mala alimentación y al consumo de tabaco y alcohol, entre otros (7).

PREVALENCIA DE ENFERMEDADES Y CONDICIONES ORALES (\%) ENTRE LOS AÑOS 2007 - 2010

\begin{tabular}{|l|l|l|l|l}
\hline Edad (años) & Caries & $\begin{array}{l}\text { Enfermedad } \\
\text { periodontal }\end{array}$ & $\begin{array}{l}\text { Desdentamiento } \\
\text { parcial }\end{array}$ & $\begin{array}{l}\text { Desdentamiento } \\
\text { total }\end{array}$ \\
\hline $35-44$ & $99,2 \%$ & $93,5 \%$ & $79,7 \%$ & $0,4 \%$ \\
\hline
\end{tabular}

(7)

Seis consecuencias de la pérdida parcial de los dientes naturales:

1. Alteraciones estéticas y fonéticas (del habla)

2. Disminución de la eficacia de la masticación

3. Alteración de la posición de los dientes restantes

4. Atrición dental (desgaste dental)

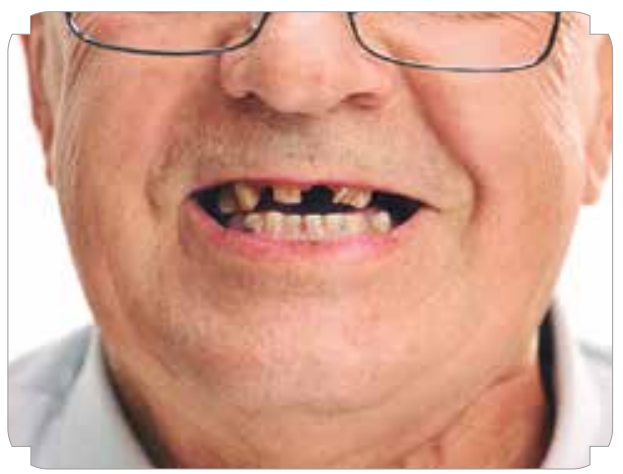

5. Enfermedad periodontal

6. Disfunción (alteración de la función) de la articulación temporomandibular (puede haber dolor, ruidos y alteraciones de la función de la articulación de la mandíbula) 


\section{¿QUÉ EFECTOS TIENE EL TABACO SOBRE NUESTRA SALUD ORAL?}

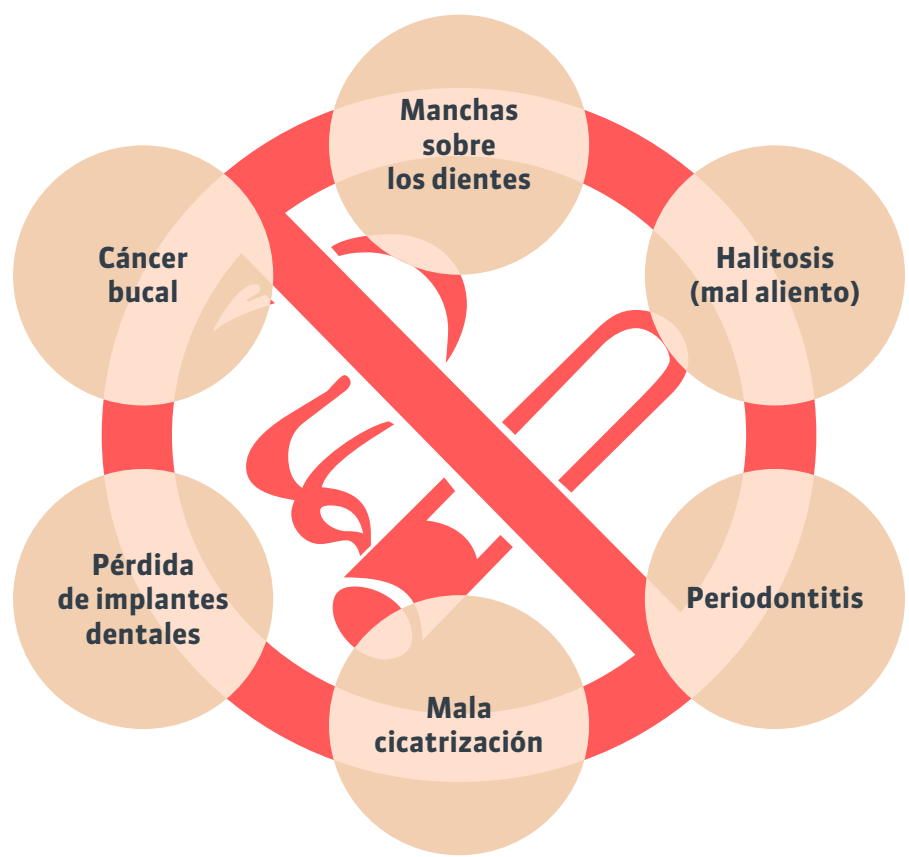

Chile presenta un 40\% de prevalencia de consumo de tabaco en la población mayor de 15 años; y de un 35,1\% en jóvenes de 13 a 15 años (6).

El humo de los cigarrillos está compuesto por unos cuatro mil constituyentes tóxicos, mutagénicos y carcinogénicos, por lo que es innegable el efecto perjudicial del hábito tabáquico sobre la salud bucal (6) (12).

La periodontitis (enfermedad periodontal) es la principal patología asociada al tabaquismo y progresa con mayor rapidez en un fumador, provocando un fracaso de los tratamientos periodontales e implantes (se producen dificultades para que este se una al hueso y los implantes se pierden más tempranamente). Mientras más cigarrillos consume un fumador, mayor es el daño en los tejidos periodontales. No obstante, el tabaco es un enemigo silencioso, por ejemplo, de las encías; estas pueden lucir no inflamadas a pesar de estar enfermas debido al menor aporte sanguíneo y de oxígeno provocado por el tabaco (6) (12).

Entre las enfermedades de la mucosa, asociada al hábito tabáquico, se encuentra la queratosis nicotínica del paladar (paladar blanco con puntos rojos); la melanosis del fumador (mucosas más oscuras); la leucoplasia (lesión en mucosa de color blanco) y el cáncer de mucosa oral. Además, la reparación de heridas de la mucosa está retardada, se promueve la inflamación crónica sistémica, se observan tinciones o manchas dentarias, halitosis (mal aliento), mayor formación de cálculo dental o sarro y una disminución de la capacidad olfatoria y gustativa (6) (12). 


\section{CÁNCER ORAL}

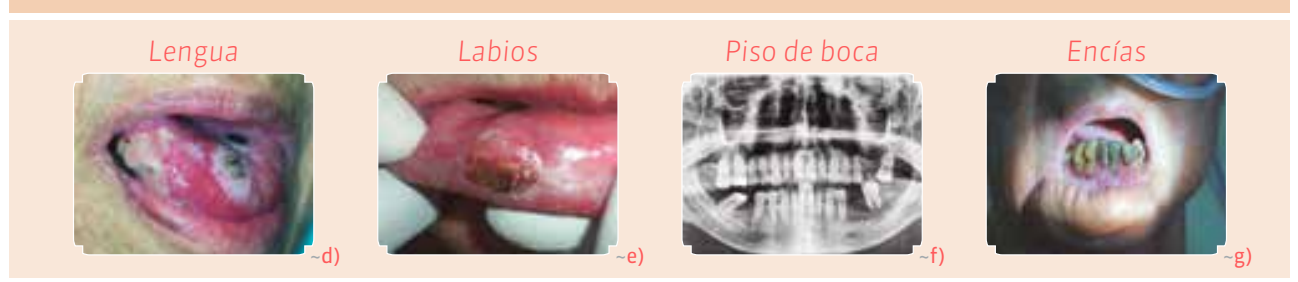

\section{¿Qué es anormal?}

- Heridas que no cicatricen por más de dos semanas

- Cambios de color en mucosas: blanco, rojo, mixto o negro

- Mucosas con cambio de forma y consistencia

- Dificultad para mover la lengua

- Dificultad para masticar o tragar alimentos

- Bultos anormales en la boca y/o cuello

\section{Prevención del cáncer oral}

- Deja el consumo de tabaco y alcohol

- Proteje tus labios de la exposición solar

- Mantén una buena higiene oral

- Visita regularmente a tu dentista

- Realiza autoexamen periódicamente

\section{(13) (6) (12)}

\section{Higiene oral}

Una de las técnicas de cepillado dental más recomendadas es la “Técnica de Bass modificada”. En esta técnica se debe posicionar la cabeza del cepillo inclinada hacia las raíces, en un ángulo de 45 grados. Luego, se deben realizar movimientos verticales cortos y, a la vez, movimientos de rotación (circulares). Para las caras oclusales o masticatorias de los dientes, se recomiendan movimientos cortos de barrido, de adelante hacia atrás. Además, se debe cepillar la lengua. 
Es recomendable utilizar un cepillo humedecido con agua y de características (mango y cabezal) acorde al tamaño del usuario, procurando que los filamentos del cepillo sean suaves para no dañar encías y dientes. El cepillado dental se debe realizar al menos tres veces al día, esto es: posterior al desayuno, luego del almuerzo y antes de acostarse. Después de cada comida, se debe esperar al menos 30 minutos antes del cepillado, esto porque hay que dejar que la saliva actúe sobre los ácidos generados dentro de la boca y así no dañar nuestros dientes.

Para prevenir las caries interproximales, que son las que se encuentran entre los dientes, es necesario utilizar seda dental, en lo posible, todas las noches luego del cepillado nocturno.

\section{•) ADULTOS MAYORES}

Adulto mayor es toda persona que ha cumplido 60 años, sin diferencia entre hombres y mujeres. A nivel mundial, se observa una tendencia sostenida al aumento de la expectativa de vida al nacer y un incremento porcentual de la población de 60 y más años. Chile también está viviendo este proceso de transición demográfica hacia el envejecimiento ya que, de acuerdo con datos obtenidos de los censos de población, en 100 años, la población de mayores de 60 años creció siete veces y media y se estima que, hacia el año 2034, la cantidad de adultos mayores igualará a la cantidad de menores de 15 años (14).

Si bien, hace algunos años, la salud oral de los adultos mayores se centraba en la pérdida de dientes, actualmente se observa una mayor conservación de las piezas dentales, por lo que los problemas asociados al envejecimiento se relacionan con caries,

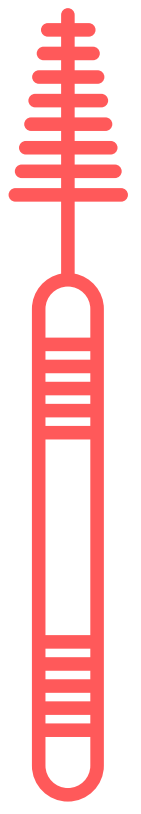

atrición dental (desgaste natural de las superficies de los dientes), enfermedad periodontal (enfermedad de las encías y los tejidos que rodean al diente), xerostomía (sensación de boca seca), ardor en la boca, halitosis (mal aliento), micosis (hongos), patologías (enfermedades) asociadas a prótesis removibles, entre muchas otras enfermedades y condiciones orales (14). 
PREVALENCIA DE ENFERMEDADES Y CONDICIONES ORALES (\%) ENTRE LOS AÑOS 2007 - 2010

\begin{tabular}{|l|l|l|l|l}
\hline Edad (años) & Caries & $\begin{array}{l}\text { Enfermedad } \\
\text { periodontal }\end{array}$ & $\begin{array}{l}\text { Desdentamiento } \\
\text { parcial }\end{array}$ & $\begin{array}{l}\text { Desdentamiento } \\
\text { total }\end{array}$ \\
\hline $65-74$ & $99,4 \%$ & $97,6 \%$ & $69,8 \%$ & $29,1 \%$ \\
\hline
\end{tabular}

(7)

\section{Higiene oral}

Para aquellos adultos mayores desdentados parciales, la técnica de cepillado dental es la misma que se detalla en adultos, es decir, se podría recomendar la "Técnica de Bass modificada".

\section{Consejos para los portadores de prótesis dentales:}

1. Utilizar un cepillo suave para cepillar dientes naturales. Realizando la "Técnica de Bass modificada"; también cepillarse en las áreas donde se perdieron dientes.

2. Higienizar la prótesis al menos dos veces al día, con un cepillo medio/duro (exclusivo para este uso), agua y jabón líquido neutro. Cepillar las superficies internas y externas de la prótesis. No usar pasta dental para cepillar la prótesis removible porque puede rayarse.

3. No se debe utilizar al dormir. Las prótesis acumulan restos de comida lo que puede generar inflamación de los tejidos bucales. Siempre dejar la prótesis en un lugar limpio y seco por las noches.

4. Se puede utilizar pastillas efervescentes (por efecto antifúngico, antibacteriano o limpiador) para una mejor higiene de la prótesis. Una vez a la semana y siguiendo las instrucciones de uso del fabricante.

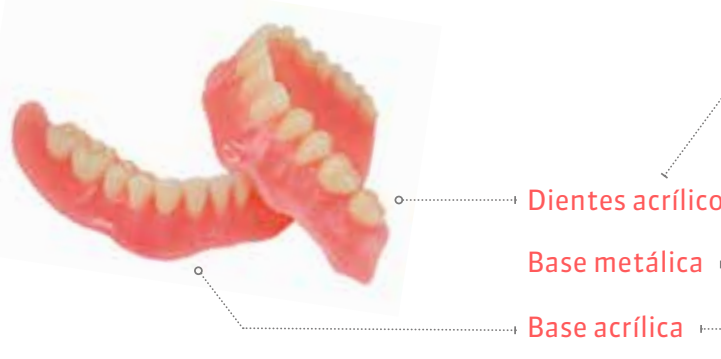

Prótesis total removible

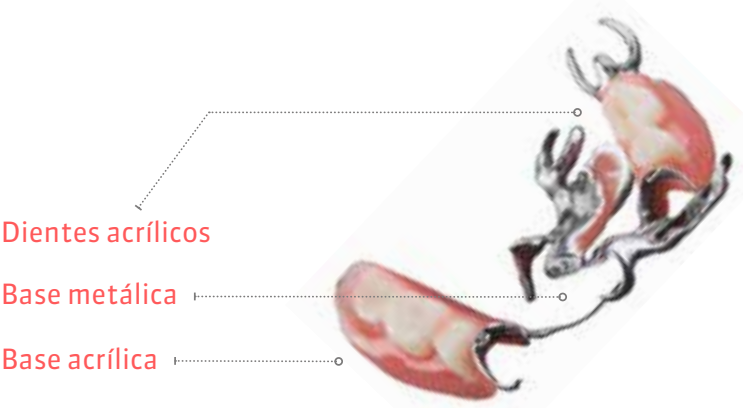

Prótesis parcial removible
En prótesis que tengan partes metálicas, evitar el uso de cloro ya que este afecta el metal. Solo si es una prótesis completa de acrílico, se puede sumergir en un vaso con agua y cinco gotitas de cloro, una vez por semana, durante la noche. 


\section{Capítulo 2 \\ De acuerdo con mi situación de salud general y la de mi boca}

En este capítulo se sintetizan situaciones bucales y de otra índole, relacionadas con la salud general que, de manifestarse, podrían sugerir acudir a una consulta dental. 


\section{Capítulo 2}

\section{De acuerdo con mi situación de salud general y la de mi boca}

\section{-) CUANDO TENGO \\ ALGUNA CONDICIÓN ORAL PREVIA}

\section{Caries dental}

Enfermedad de múltiples factores que da origen a las lesiones de caries. Proceso infeccioso localizado en el diente, de origen multifactorial, y que es causado principalmente por bacterias, una dieta alta en azúcares y una pobre higiene oral. Se observa un reblandecimiento del tejido duro del diente, que puede evolucionar hasta la formación de una cavidad (15).
La caries es una de las causas más frecuentes de dolor dental, lo que la posiciona como una enfermedad invalidante para quien la porta. De ahí la importancia por la mantención de buenos hábitos de higiene oral y la asistencia periódica al dentista para no permitir su avance (15).

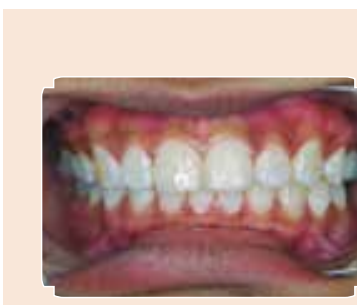

Mancha blanca

\section{LAS ETAPAS DEL DESARROLLO DE LAS CARIES}
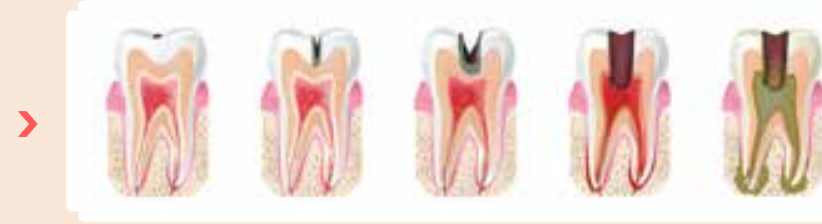

Caries en esmalte, en dentina y con compromiso pulpar

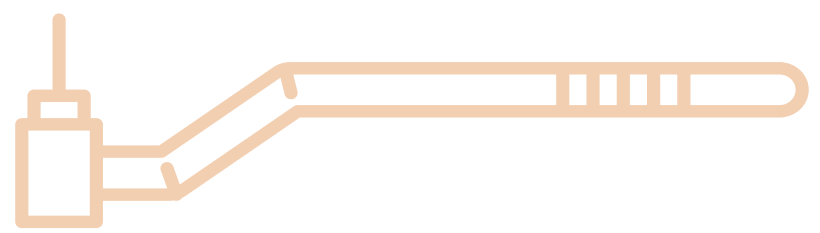




\section{Enfermedad periodontal}

Las enfermedades periodontales son aquellas condiciones inflamatorias crónicas que afectan a los tejidos de soporte y protección de los dientes (encías y hueso). Las más comunes son la gingivitis, inducida por placa bacteriana, y la periodontitis crónica.

Generalmente, las enfermedades periodontales comienzan con encías enrojecidas y sangrantes. Algunas veces esta infección evoluciona a la pérdida de hueso que rodea el diente, manifestándose múltiples signos de destrucción, siendo uno muy común el aumento de movilidad dentaria

La gingivitis es una inflamación de las encías causada por acumulación de placa bacteriana. Las encías se observan hinchadas, de coloración rojiza y sangran con facilidad. Esta enfermedad es reversible si se mantienen buenos hábitos de higiene oral y un tratamiento odontológico adecuado (16).

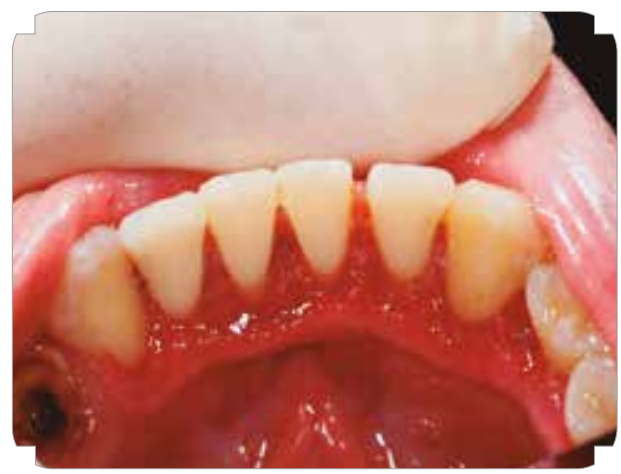

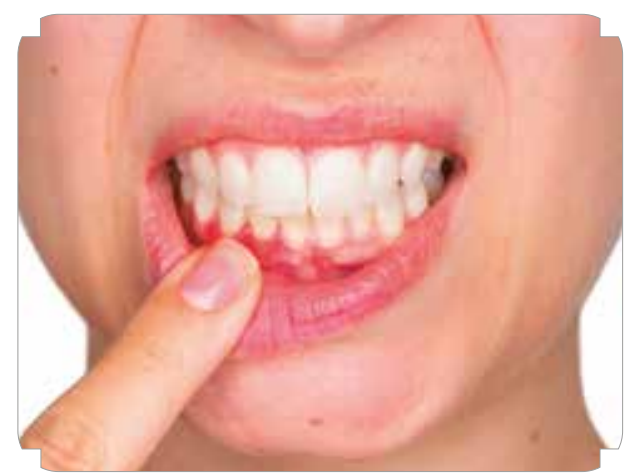

Si la gingivitis no es resuelta, esta podría progresar a una periodontitis crónica, la que se caracteriza por sangrado y retracción de encías, halitosis (mal aliento) y pérdida del hueso que rodea los dientes. Esto último podría provocar movilidad dental, con la consecuente pérdida de una o más piezas. Los efectos de esta enfermedad son irreversibles, por lo que un tratamiento odontológico adecuado y buenos hábitos de higiene oral podrían detener el progreso de esta, pero no revertir sus daños (17). 
Anomalías dentomaxilares (ADM)

Las anomalías dentomaxilares son alteraciones en la posición de los dientes y/o los huesos maxilares. Las ADM se observan como maloclusiones (mal posición dentaria) que repercuten en la forma, función y estética del sistema masticatorio. Su causa es multifactorial, existiendo factores sistémicos, hereditarios y congénitos. También existen factores locales, como la pérdida prematura de dientes temporales por trauma o caries, restauraciones ("tapaduras") inadecuadas, malos hábitos orales, entre otros.

\section{Hiposalivación y Xerostomía}

La saliva tiene muchas funciones. Entre ellas, destaca su papel de protección ante la aparición de enfermedades debido a algunos elementos que la componen. Generalmente, las personas que tienen poca saliva tienden a sufrir, con más frecuencia, algunas enfermedades de la boca.

La hiposalivación o hiposialia es la disminución del flujo salival, mientras que xerostomía es la sensación de sequedad bucal. La disfunción (función alterada) salival en gente mayor es, usualmente, una consecuencia de la ingesta de medicamentos usados para tratamientos de enfermedades sistémicas. Las drogas anticolinérgicas, los antidepresivos tricíclicos, sedantes, antihistamínicos, antihipertensivos y antiparkinsonianos son algunos de los fármacos que afectan la calidad y cantidad de la saliva. Por otro lado, la radioterapia de cabeza y cuello y agentes quimioterapéuticos también han sido asociados con desórdenes salivales, causando daño permanente a las glándulas del mismo nombre (18) (19).
De esta forma, la salud oral se ve deteriorada por la hiposalivación y/o xerostomía, presentando problemas como:

> Mayor susceptibilidad a la caries dental y enfermedad periodontal.

$>$ Dificultades al comer alimentos, principalmente alimentos secos, lo que causa un deterioro de su estado nutricional.

> Dificultades en el habla debido a que la lengua "se pega" en el paladar.

> Alteraciones en el gusto.

> Disminución de la retención de prótesis removibles para quienes las portan.

$>$ Incremento del riesgo de infecciones orales como la candidiasis pseudomembranosa (infección oral causada por hongos).

Trastornos temporomandibulares (TTM) Los trastornos temporomandibulares se definen como "un grupo de alteraciones que afectan a los músculos masticadores, las articulaciones temporomandibulares y sus estructuras anexas" (18).

Actualmente, aún existe controversia respecto a las causas de los TTM, por ello es que se prefiere hablar de factores de riesgo, los que, asociados a otros factores, pueden desencadenar la patología. Dentro de estos se encuentran la sobrecarga muscular repetitiva, las interferencias oclusales, los estados psíquicos alterados, ciertas enfermedades sistémicas, traumas con relación al sistema masticatorio o terapias equivocadas ante un trastorno temporomandibular (18). 
Los TTM pueden presentar dolor, ruidos articulares y limitaciones funcionales. Ante cualquiera de estos síntomas se debe consultar a un odontólogo (18).

\section{Bruxismo}

El término bruxismo, comúnmente conocido como "apriete dentario", significa refregar dientes y corresponde a una actividad no funcional que se produce en ausencia de la masticación de alimentos. El bruxismo puede ocurrir durante el día y/o durante la noche (al dormir), siendo esto último mucho más frecuente. Las maloclusiones, malos hábitos orales, trastornos temporomandibulares y estados emocionales alterados pueden contribuir al desarrollo de esta actividad (18).

El bruxismo se traduce en una sobrecarga de las estructuras dentarias, musculares y/o articulares, pudiendo apreciarse consecuencias como daño de las estructuras articulares, periodontales, neuromusculares y/o dentarias (provocando destrucción e hipersensibilidad dentaria, fracturas de restauraciones y prótesis, entre otros) (18).

Los tratamientos son variados. Algunos apuntan al manejo de los niveles de estrés, a mejorar la calidad del sueño, a la modificación conductual y a realizar ejercicios de reeducación neuromuscular. Otros tratamientos, ampliamente usados, incluyen las férulas oclusales (mal llamados "planos de relajación”) aunque, en el último tiempo, su uso ha generado controversia entre los profesionales (18).

En la actualidad, el uso de férulas está restringido a algunos tipos de condiciones o patologías orales, y definitivamente no soluciona el bruxismo, por lo que no es un dispositivo que se pueda autoindicar, sino que debe estar supervisado por un cirujano dentista.

\section{Trauma dentoalveolar (TDA)}

El trauma dentoalveolar (TDA) corresponde a una lesión traumática, producto de un impacto violento, que afecta al diente propiamente tal y a las estructuras de soporte que lo rodean (20).

Entre el 4 y el $30 \%$ de los niños ha sufrido algún traumatismo en los dientes anteriores, siendo estos más frecuentes en hombres entre los 7 y 10 años, debido a golpes - caídas. En la dentición secundaria, la lesión más frecuente es la fractura coronaria, con un 51,9\% del total de los TDA (20).

Un trauma dentoalveolar puede presentar características como dolor, inflamación, pérdida o disminución de la función de masticación, sangrado, desplazamiento de piezas dentarias, deformación de la oclusión y pérdida de tejidos (20).

Para evitar complicaciones futuras, por toda lesión traumática se debe consultar oportunamente a un dentista, incluso si no se presenta dolor o sangrado. En el caso de los niños, las consecuencias de los traumatismos dentoalveolares se pueden manifestar años más tarde, en el momento de la erupción de los dientes secundarios (20). 


\section{Prótesis removible}

u otro aparato removible oral

Las prótesis removibles dentales reemplazan las piezas dentales perdidas por caries, enfermedad periodontal o por algún golpe, restaurando la función masticatoria, fonética y la estética del sistema masticatorio.

Una vez instalada la prótesis removible u otro aparato removible, este retendrá gran cantidad de placa bacteriana, por lo que expondrá a la cavidad bucal a una mayor susceptibilidad frente a la caries, enfermedad periodontal, infecciones por hongos, etc. Lo anterior hace indispensable que el portador de aparatos removibles tenga una correcta higiene oral y acuda a los controles periódicos con el especialista porque, posterior a su instalación, estos aparatos requieren de ajustes y con el paso del tiempo también se producirán desadaptaciones a los tejidos de la cavidad oral.

\section{-) CUANDO TENGO ALGUNA CONDICIÓN DE SALUD GENERAL}

La evidencia científica ha demostrado firmemente la interrelación entre salud bucal y salud general. Las enfermedades bucales se han relacionado con enfermedades neurodegenerativas, enfermedades cardiovasculares, diabetes, entre otros. Además, la cavidad bucal es el primer lugar donde pueden diagnosticarse enfermedades como deficiencia de vitamina B-12, desórdenes alimenticios y los primeros signos clínicos de VIH. Estilos de vida saludables asociados a salud bucal, pueden ayudar a reducir el riesgo de enfermedades crónicas en el desarrollo de los pacientes y mejorar su salud sistémica.

\section{Embarazo}

La atención odontológica de la embarazada debe apuntar a reducir los riesgos para la madre y el (la) hijo (a) por nacer. Esto por el impacto que tiene la salud bucal de la gestante, tanto para su propia salud, como para la salud oral de su hijo o hija (esto por el riesgo de desarrollar caries temprana de la infancia) (21).

Se ha demostrado que una madre con alta prevalencia de caries puede infectar con ciertas bacterias a su hijo. Por otro lado, muchas mujeres incrementan la ingesta calórica durante el embarazo, frecuentemente aumentando el consumo de comida basada en carbohidratos, exponiendo sus dientes a altos niveles de acidez, lo que a su vez fomenta el riesgo de caries (18).

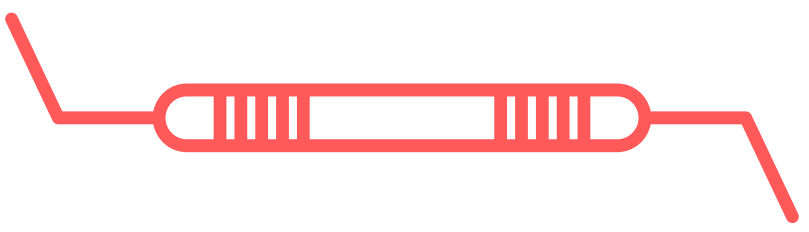


En un 9,6\% de las pacientes embarazadas se puede observar un granuloma piogénico gravídico (hiperplasia o tumor de crecimiento lento e indoloro, localizado en la encía), que aparece comúnmente durante el segundo trimestre de embarazo. Luego del parto, la mayoría de las lesiones tienden a resolverse, pero si este granuloma interfiere con la masticación o con una adecuada higiene debe ser removido (18).

No obstante lo anterior, la complicación más común en las embarazadas es la inflamación generalizada de las encías o gingivitis inducida por placa bacteriana. Estos cambios inflamatorios se deben a un aumento exacerbado en la síntesis de estrógeno, progesterona y prostaglandinas, pobre higiene oral y acumulación de placa dental (18).

\section{Diabetes Mellitus (DM)}

La diabetes mellitus es un desorden endocrino genético complejo multifactorial, que se presenta por una anormalidad en el metabolismo de la glucosa (azúcar) debido a una deficiencia de insulina o fallas en el metabolismo de esta (18).

Diversos estudios relacionan directamente la DM con la enfermedad periodontal. La DM puede afectar la progresión y severidad de la enfermedad periodontal y, a su vez, la enfermedad periodontal puede agravar la DM e incrementar el riesgo de disfunción renal y cardiovascular, complicando el cuadro sistémico general del paciente (18).

En cuanto a la relación de la diabetes con la caries dental, se ha encontrado un aumento de la aparición de caries asociado con DM mal controladas, debido a la presencia de altos niveles de glucosa en la saliva. Por otro lado, el paciente diabético bien controlado experimenta una disminución en la aparición de caries puesto que reduce la ingesta de carbohidratos, presenta un control metabólico efectivo y una actitud responsable frente a su salud oral (18).

\section{Enfermedades cardiovasculares}

Son múltiples las repercusiones que tiene la mala salud bucal sobre las enfermedades sistémicas. Dentro de estas se encuentra la vinculación entre la enfermedad periodontal y el riesgo aumentado de padecer arteriosclerosis, infarto de miocardio y accidentes vasculares cerebrales (22).

Investigaciones recientes han revelado que quienes presentan una infección periodontal tienen $20 \%$ menos probabilidad de tener una presión arterial en rangos saludables que quienes tienen correctos hábitos de salud oral (22).

En la actualidad, estudios han sugerido que el estilo de vida vinculado al síndrome metabólico (definido como la presencia de obesidad, hipertensión arterial, diabetes, triglicéridos elevados y/o colesterol elevado), está en la base de enfermedades periodontales y cardiovasculares, por lo que un cambio en los hábitos permitiría ayudar a prevenirlas de forma paralela. Es decir, la periodontitis podría beneficiarse de modificaciones en el estilo de vida, que van más allá de cepillarse correctamente los dientes y encías, y que tiene que ver con una alimentación saludable y realización de actividad física de forma regular. Asimismo, la higiene bucal podría tener especial importancia en la salud cardiovascular, independientemente del control de los factores de riesgo cardiovasculares tradicionales (22). 
Virus de Inmunodeficiencia Humana (VIH) EI VIH o Virus de la Inmunodeficiencia Humana es un retrovirus que ataca al sistema inmune de la persona infectada. La fase de SIDA o Síndrome de la Inmunodeficiencia Adquirida se observa como consecuencia del grave deterioro del sistema inmunológico, en donde surgen las enfermedades oportunistas y/o neoplasias. En esta fase, si la persona no es debidamente tratada, desarrollará enfermedades que le pueden provocar la muerte (23).

Si bien no hay contagio de VIH a través de la saliva, sí hay riesgo de contagio de otras patologías a través de esta, las que están asociadas, muchas veces, a pacientes infectados de VIH, como por ejemplo siffilis, hepatitis, tuberculosis, entre otras. La indicación para la prevención de estas patologías es la práctica de sexo oral con preservativo.

En boca se pueden manifestar tempranamente varias patologías asociadas con VIH-SIDA, las que son indicativas del deterioro del sistema inmunológico. Las primeras y más habituales manifestaciones son infecciones por hongos o candidiasis (se observan manchas blancas, principalmente en el paladar, que se pueden desprender al raspado) e infecciones virales, como el herpes, o presencia de lesiones provocadas por virus papiloma. Todas estas lesiones deben ser evaluadas y confirmadas por un odontólogo (23).

\section{Condiciones orales como marcadores de inmunodepresión}

Leucoplasia pilosa

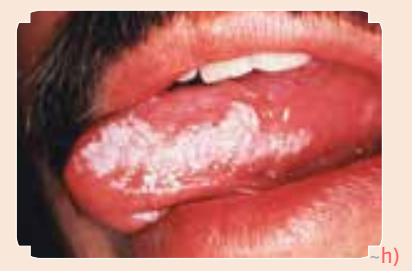

Candidiasis oral

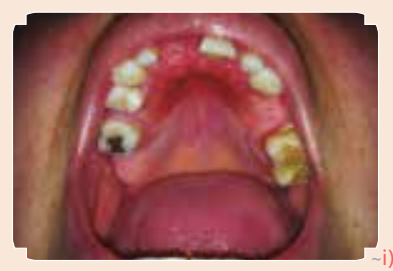

Papiloma

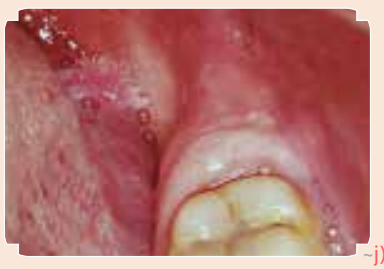

Úlceras orales (HSV-7)

Sarcoma de Kaposi
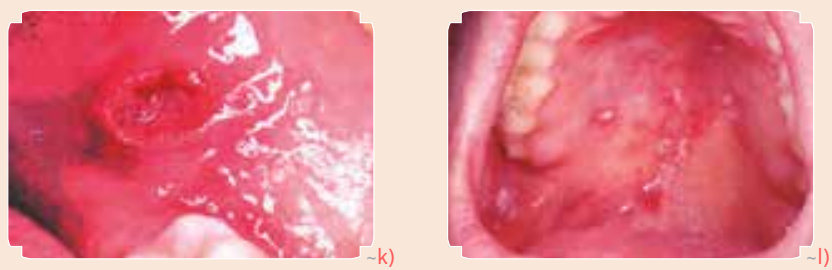

Además, en un paciente con inmunosupresión, infecciones como la enfermedad periodontal o las caries suelen ser más severas y de avance más rápido. 
Pacientes con necesidades especiales

Los pacientes con necesidades especiales son aquellos que poseen dificultades (físicas, mentales, sensoriales, del desarrollo, conductuales, emocionales, déficit cognitivo) y condiciones limitadas que requieren atención médica (alteraciones sistémicas, que necesiten de programas o servicios especializados en el tratamiento) (24).

Las diversas condiciones del paciente pueden causar limitaciones en relación con las actividades cotidianas. Entre los problemas más habituales, en cuanto a la salud bucal, se observa lo siguiente:

> Enfermedades derivadas de una mala higiene oral (caries, enfermedad periodontal, etc.)

> Falta de dientes en edades tempranas debido a su condición o por efectos de la medicación a la que en muchos casos están sometidos.

> Bruxismo.

> Hipersensibilidad dentaria (sensibilidad dentaria aumentada).

> Problemas nutricionales y de deglución.

> Dificultad en la expresión verbal (24).

Los pacientes con necesidades especiales muchas veces pueden requerir de sedación, anestesia general o el uso de otras técnicas que permitan un correcto tratamiento odontológico. Por otro lado, con el fin de prevenir enfermedades bucales, es fundamental el acompañamiento por parte del entorno familiar y el equipo médico y odontológico, así como el asistir periódicamente a controles dentales y seguir correctamente las indicaciones del dentista para el cuidado bucal de estos pacientes (24). 


\section{-> CUANDO ESTOY TOMANDO CIERTOS MEDICAMENTOS}

Que provocan agrandamiento gingival Algunos medicamentos son capaces de generar una deformación del tamaño y forma de la encía. Esto se presenta generalmente en pacientes jóvenes y suele manifestarse a los tres meses de uso del fármaco. Una vez que se presenta el agrandamiento, el control de la higiene es capaz de ayudar levemente, puesto que la eliminación del mismo solo se podrá realizar quirúrgicamente. Si el tratamiento farmacológico continúa, el agrandamiento gingival podría presentarse nuevamente (16).
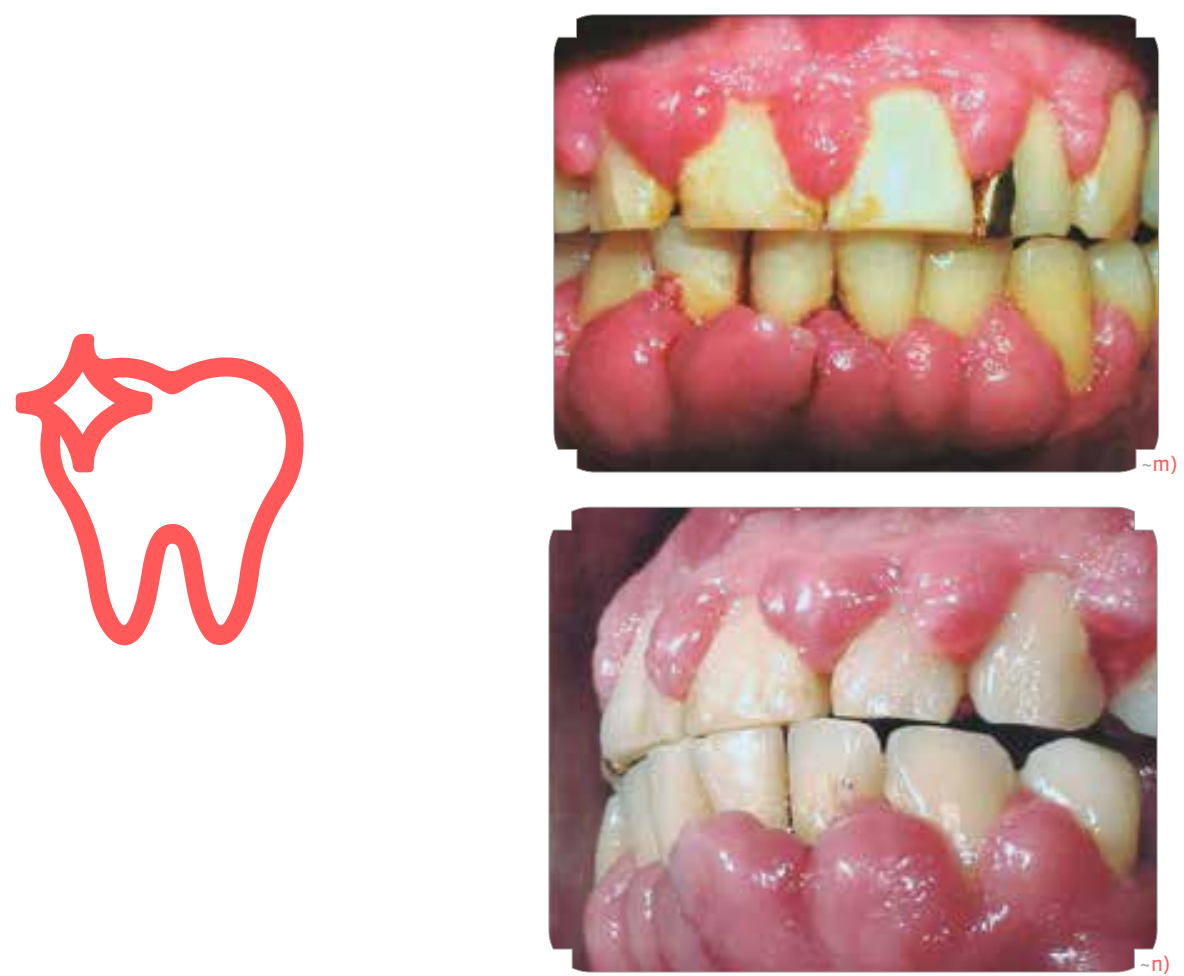

Agrandamiento gingival asociado a la toma de anticonvulsivantes. 


\section{Fármacos que podrían provocar agrandamiento gingival}

$\begin{array}{rll}\text { ANTICONVULSANTES } & \longrightarrow & \text { Fenotoína } \\ \text { INMUNOSUPRESORES } & -\longrightarrow & \text { Ciclosporina A } \\ \text { BLOQUEADORES DE CALCIO } & \longrightarrow & \text { Nifedipino, Verapamilo, Diltiazem }\end{array}$

Que provocan xerostomía

La xerostomía y la hiposialia pueden ser causadas por enfermedades sistémicas como el síndrome de Sjögren, amiloidosis, sarcoidosis, infección por VHC (virus de la hepatitis C) y VIH, parotiditis transitoria (viral o bacteriana), cirrosis biliar, fibrosis quística, diabetes mellitus, agenesia glandular, depósito de hierro (talasemia), etc. La disminución del flujo salival también puede ocurrir por causas como la deshidratación, diarrea y/o vómitos persistentes, déficit proteicos, alteraciones cardíacas,

\section{Fármacos xerostomizantes}

\author{
- Antidepresivos tricíclicos \\ - Antiespasmódicos \\ - Neurolépticos \\ - Inhibidores de la MAO \\ - Agentes antiparkinsonianos \\ - Litio \\ - Agonistas adrenérgicos centrales \\ - Diuréticos \\ - Descongestionantes nasales \\ - Antihistamínicos \\ - Broncodilatadores \\ - Descongestivos - anticatarrales \\ -Anorexígenos (anfetaminas)
}

uremia y edema. Además, obstrucciones de los conductos de las glándulas salivales (sialolitiasis), obstrucción nasal, el uso de inhaladores, padecer estrés o depresión severa, y consumir alcohol y tabaco también pueden ser la causa de sufrir xerostomía o hiposialia (19).

Por otro lado, existen más de cuatrocientos medicamentos que inducen a una función disminuida de las glándulas salivales, siendo un efecto secundario de estos (19) (18).

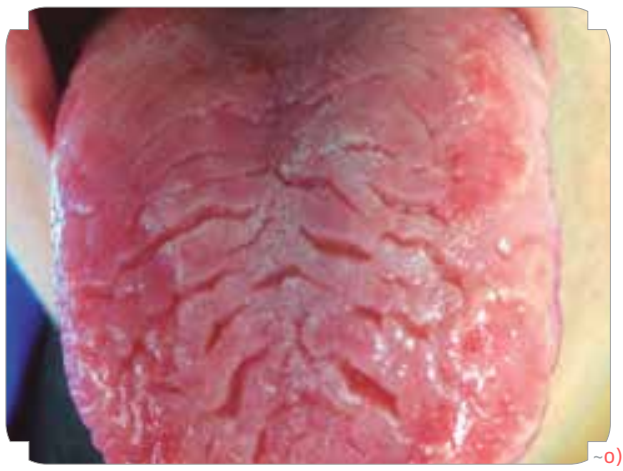

Lengua fisurada, sin papilas y saburral (capa blanquecina sobre la lengua, vinculada a mala higiene) en paciente con xerostomía asociada a medicamentos depresivos. 


\section{Bifosfonatos}

Los bifosfonatos son medicamentos que previenen la pérdida ósea y reducen las fracturas, por lo mismo son ampliamente utilizados en diversas patologías óseas como en el tratamiento de la osteoporosis, la enfermedad de Paget, la hipercalcemia tumoral maligna, metástasis óseas y en lesiones osteolíticas del mieloma múltiple (18) (25).

Asociado al consumo de estos fármacos se han identificado lesiones en el territorio bucal, que corresponden a exposiciones óseas de los huesos maxilares, lo cual se denomina osteonecrosis de los maxilares inducida por bifosfonatos (ONMB). La ONMB es una lesión de lenta progresión, sin tendencia a la curación espontánea, que puede incluso originar fracturas mandibulares (18) (25).

Dentro de los factores de riesgo para el desarrollo de la ONMB, se encuentran la terapia concomitante con esteroides, quimioterapia y bifosfonatos endovenosos, las exodoncias, enfermedades infecciosas, trauma, enfermedad periodontal, procedimientos dentales invasivos, prótesis dentales, abuso de alcohol y tabaco, malnutrición, entre otras (18) (25).

Es fundamental que los pacientes que comenzarán un tratamiento con bifosfonatos sean derivados al odontólogo de forma previa, para que su cavidad bucal se encuentre en las mejores condiciones posibles para así recibir el medicamento con el menor riesgo para su salud (18) (25).

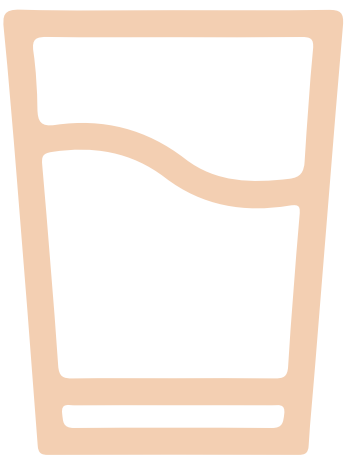




\section{Capítulo 3 \\ De acuerdo con mi riesgo}

En este capítulo se

explican algunas

condiciones biológicas

y situaciones sociales

que podrían aumentar

la probabilidad de tener

mayores problemas

de salud bucal, y que

justificarían la consulta

a un dentista. 


\section{De acuerdo con mi riesgo}

\section{•) RIESGO PSICOSOCIAL}

Las enfermedades bucales no son un fenómeno exclusivamente biológico, sino que también poseen un gradiente psicológico y social importante, es decir, se entiende la salud y la enfermedad como un continuo, que es parte de un modelo biopsicosocial.

Actualmente, el modelo de salud se fundamenta en una atención integrada, con enfoque familiar y comunitario. Específicamente, en salud bucal, el último informe de la Organizaión Mundial de la Salud (OMS) reconoce que "el mayor riesgo para la salud oral está en los determinantes socioculturales: condiciones de vida en pobreza, bajo nivel educativo, creencias, tradiciones y cultura de salud oral" (26).

Los determinantes sociales de la salud se entienden como las condiciones sociales en que las personas viven y trabajan, que impactan sobre la salud, y son susceptibles de modificación mediante intervenciones efectivas. Algunos determinantes sociales de la salud son, por ejemplo: el acceso a los servicios de salud, nivel socioeconómico, ingresos económicos, educación, condiciones de trabajo, condiciones de vivienda, etc.
Riesgo biopsicosocial y caries dental La caries dental es la enfermedad oral más prevalente en la población a nivel mundial y relaciona, a su aparición y desarrollo, los siguientes factores de riesgo psicosociales:

> Factores ambientales: ubicación geográfica.

> Regímenes políticos: sistemas de salud y servicios de salud oral, disponibilidad de los servicios de salud.

> Factores socioeconómicos: educación, ingresos, ocupación.

$>$ Factores socioculturales: estilos de vida, comportamiento y creencias, raza/etnia (26). 
De acuerdo con un estudio realizado el año 2007 en niños de seis años, se observa que quienes están libres de caries pertenecen, en un mayor porcentaje, al estrato socioeconómico alto, mientras que la severidad de la caries, medida con el índice ceod (índice que representa la cantidad de dientes primarios cariados, extraídos y obturados en uno o varios sujetos estudiados) es mayor en los estratos socioeconómicos bajos. Por otro lado, un mayor porcentaje de niños que pertenecen a zonas urbanas están libres de caries, y quienes pertenecen a zonas rurales tienen mayores índices de severidad de estas.

\section{SEGÚN NIVEL SOCIO ECONÓMICO (NSE)}

\begin{tabular}{l|l|l}
\hline & NSE Alto & NSE Bajo \\
\hline Libres de historia de caries (sanos) & $59,7 \%$ & $22,1 \%$ \\
\hline Severidad (índice ceod) & 1,36 & 4,42 \\
\hline
\end{tabular}

SEGÚN UBICACIÓN GEOGRÁFICA

\begin{tabular}{l|l|l} 
& Zonas urbanas & Zonas rurales \\
\hline Libres de historia de caries (sanos) & $32,3 \%$ & $15,3 \%$ \\
\hline Severidad (índice ceod) & 3,46 & 5,06 \\
\hline
\end{tabular}

(13)

Los datos expuestos muestran cómo los factores socioeconómicos tienen un potente impacto en los factores biológicos. Es por esto que las políticas públicas se han enfocado, principalmente, en entregar mayor acceso a la salud oral a las personas de los niveles socioeconómicos más bajos. 


\section{•> CUANDO TENGO RIESGO BIOLÓGICO}

La evaluación del riesgo biológico de cada individuo se analiza en un ámbito general y en un ámbito específico.

El riesgo biológico general hace referencia a todas las condiciones sistémicas, enfermedades y uso de fármacos de una persona, y se evalúa a través de la historia clínica del paciente. Enfermedades como diabetes mellitus, VIH-SIDA, enfermedades cardiovasculares, enfermedad de reflujo gastroesofágico o enfermedades respiratorias, tienen repercusiones a nivel oral; al igual que el consumo de ciertos fármacos, que pueden provocar agrandamiento gingival o xerostomía, o el uso de bifosfonatos.

Por otro lado, el riesgo biológico específico hace referencia a las condiciones orales, lo cual se evalúa comúnmente a través del riesgo cariogénico.

\section{Riesgo cariogénico}

El riesgo cariogénico es la probabilidad que un individuo desarrolle lesiones de caries en un período específico de tiempo. Basado en los distintos factores de riesgo, el riesgo cariogénico puede ser alto, moderado o bajo. De acuerdo con esto, el odontólogo tomará decisiones para realizar el tratamiento más adecuado (27) (28).

\section{Factores de riesgo cariogénico:}

$>$ Dieta: depende del tipo de carbohidrato fermentable que se ingiere, de sus características (por ejemplo, si es adhesivo), de la cantidad, frecuencia y momento de consumo de los carbohidratos, etc. 
$>$ Microorganismos (bacterias): estos se encuentran en la placa bacteriana.

> Factores del hospedero: saliva (la cual protege las superficies dentarias gracias a su capacidad de neutralizar los ácidos) y enfermedades relacionadas. Algunas enfermedades autoinmunes, inmunodeficiencia severa, terapia de radiación de cabeza y cuello, y la polimedicación pueden reducir el flujo salival.

$>$ Higiene oral (27) (28).

\section{Evaluación del riesgo cariogénico:}

$>$ Experiencia de caries: es uno de los mejores predictores de futuras lesiones de caries.

> Factores socioeconómicos: tienen un fuerte impacto sobre los factores. De esta manera se puede explicar por qué un individuo tiene una dieta cariogénica o por qué descuida su higiene oral.

> Factores biológicos: cantidad y composición de la biopelícula, la dieta y la calidad de la estructura dentaria (huésped).
Habitualmente, para facilitar la evaluación del riesgo cariogénico de cada uno de los pacientes, los dentistas utilizan un modelo computacional Ilamado Cariogram ${ }^{\oplus}$ (27) (28).

La determinación de riesgo biológico indicará cada cuánto tiempo debo visitar al dentista, lo que dependerá de si el riesgo cariogénico es alto (cada tres meses), moderado (cada seis meses) o bajo (al menos una vez al año). Además, de acuerdo con las patologías que aquejan al paciente o a los fármacos que utiliza, el dentista podrá guiar sobre las medidas preventivas que se deben tener o cuál será el tratamiento más adecuado a realizar, con el objetivo final de tener una mejor salud oral. 



\section{AYUDA MEMORIA}




\section{Ayuda memoria}

\section{•> GES ODONTOLÓGICO}

\section{¿Qué es el GES Odontológico?}

Las Garantías Explícitas en Salud (GES) constituyen un conjunto de beneficios que garantizan acceso, oportunidad, protección financiera y calidad para ochenta prestaciones médicas que permiten enfrentar distintas enfermedades y condicio- nes. El GES aplica para todas las personas afiliadas al Fondo Nacional de Salud (Fonasa) e Isapres. El GES odontológico otorga atención odontológica integral acorde a las necesidades de cada persona.

\section{¿A qué tratamientos puedo acceder?}

\begin{tabular}{|c|c|}
\hline GES ODONTOLÓGICO & PRESTACIONES \\
\hline $\begin{array}{l}\text { Atención integral para niños y } \\
\text { niñas de seis años }\end{array}$ & $\begin{array}{l}\text { Examen de salud, limpiezas, aplicación de sellantes, } \\
\text { flúor, obturaciones ("tapaduras”), radiografías, } \\
\text { exodoncias en dientes primarios, etc. }\end{array}$ \\
\hline $\begin{array}{l}\text { Atención integral de la } \\
\text { embarazada }\end{array}$ & $\begin{array}{l}\text { Examen de salud, limpiezas, aplicación de sellantes, } \\
\text { flúor, obturaciones ("tapaduras”), radiografías, } \\
\text { exodoncias, etc. }\end{array}$ \\
\hline Atención integral del adulto de 60 años & $\begin{array}{l}\text { Examen de salud, limpiezas, aplicación de sellantes, } \\
\text { flúor, obturaciones ("tapaduras"), radiografías, } \\
\text { exodoncias, endodoncias, prótesis removibles, etc. }\end{array}$ \\
\hline $\begin{array}{l}\text { Atención de urgencias } \\
\text { odontológicas ambulatorias }\end{array}$ & $\begin{array}{l}\text { Tratamiento odontológico inmediato e impostergable de } \\
\text { patologías que se manifiestan principalmente por dolor } \\
\text { agudo. } \\
\text { Patologías: } \\
\text { - Pulpitis } \\
\text { - Absceso submucoso o subperióstico } \\
\text { de origen odontogénico. } \\
\text { - Absceso de espacios anatómicos bucomáxilofaciales. } \\
\text { - Pericoronaritis aguda. } \\
\text { - Flegmones orofaríngeos de origen odontogénico. } \\
\text { - Gingivitis ulceronecrótica aguda. } \\
\text { - Complicaciones post exodoncia } \\
\text { (hemorragia post exodoncia y alveolitis). } \\
\text { - Traumatismo dentoalveolar. }\end{array}$ \\
\hline
\end{tabular}




\section{.) ¿CUÁNDO DEBO IR AL DENTISTA?}

\section{1) De acuerdo con mi edad:}

\section{Preescolares y escolares}

\begin{tabular}{|c|c|}
\hline A los seis meses & $\begin{array}{l}\text { Consulta odontológica. Generalmente coincide con la } \\
\text { aparición del primer diente primario. }\end{array}$ \\
\hline A los 12 meses & Consulta odontológica. \\
\hline A los dos años & Consulta odontológica. \\
\hline A los tres años & Consulta odontológica. \\
\hline A los cuatro años & Consulta odontológica. \\
\hline A los cinco años & Consulta odontológica. \\
\hline A los seis años & $\begin{array}{l}\text { GES "Salud Oral Integral para niños y niñas de seis } \\
\text { años". Cuando comienza el recambio dentario para una } \\
\text { dentición secundaria. }\end{array}$ \\
\hline Ante una urgencia dental & $\begin{array}{l}\text { GES “Urgencia Odontológica Ambulatoria”. Si el niño } \\
\text { presenta dolor en algún diente, mucosas o territorio } \\
\text { facial, o si ha sufrido un trauma dental producto de algún } \\
\text { golpe o caída. }\end{array}$ \\
\hline Cada seis meses para control & $\begin{array}{l}\text { El dentista determinará, de acuerdo con el riesgo } \\
\text { cariogénico de cada niño, cuál debe ser la frecuencia } \\
\text { de visita al especialista. Esta puede ser cada tres, seis } \\
\text { o } 12 \text { meses. }\end{array}$ \\
\hline
\end{tabular}

\begin{tabular}{|c|c|}
\hline \multicolumn{2}{|c|}{ Adultos } \\
\hline Embarazadas & GES “Salud Oral Integral de la Embarazada”. \\
\hline Ante una urgencia dental & $\begin{array}{l}\text { GES “Urgencia Odontológica Ambulatoria”. Si presenta } \\
\text { dolor en algún diente, mucosas o territorio facial. O si } \\
\text { ha sufrido un trauma dental producto de algún golpe } \\
\text { o caída. }\end{array}$ \\
\hline Cada seis meses para control & $\begin{array}{l}\text { El dentista determinará, de acuerdo con el riesgo } \\
\text { cariogénico de cada adulto, cuál debe ser la frecuencia } \\
\text { de visita al especialista. Esta puede ser cada tres, seis o } \\
12 \text { meses. }\end{array}$ \\
\hline
\end{tabular}




\section{Adultos mayores}

\begin{tabular}{l|l} 
A los 60 años & GES “Salud Oral Integral del adulto de 60 años” \\
\hline Ante una urgencia dental & $\begin{array}{l}\text { GES “Urgencia Odontológica Ambulatoria”. Si presenta } \\
\text { dolor en algún diente, mucosas o territorio facial. O si } \\
\text { ha sufrido un trauma dental producto de algún golpe } \\
\text { o caída. }\end{array}$ \\
\hline Cada seis meses para control & $\begin{array}{l}\text { El dentista determinará, de acuerdo con el riesgo } \\
\text { cariogénico de cada adulto mayor, cuál debe ser la } \\
\text { frecuencia de visita al especialista. Esta puede ser cada } \\
\text { tres, seis o } 12 \text { meses. }\end{array}$ \\
\hline
\end{tabular}

2) De acuerdo con mi situación de salud general y la de mi boca

\begin{tabular}{|l|}
\hline Cuando tengo alguna condición oral previa \\
Caries dental \\
\hline Enfermedad periodontal \\
\hline Anomalías dentomaxilares (ADM) \\
\hline Hiposalivación y Xerostomía \\
\hline Trastornos temporomandibulares (TTM) \\
\hline Bruxismo \\
\hline Trauma dentoalveolar (TDA) \\
\hline
\end{tabular}

\begin{tabular}{|l} 
Cuando tengo alguna condición de salud general \\
\hline Embarazo \\
\hline Diabetes Mellitus (DM) \\
\hline Enfermedades cardiovasculares \\
\hline Virus de Inmunodeficiencia Humana (VIH) \\
\hline Pacientes con necesidades especiales
\end{tabular}




\section{3) De acuerdo con mi riesgo}

\section{Cuando estoy tomando ciertos medicamentos}

Que provocan agrandamiento gingival

Que provocan xerostomía

Bifosfonatos

\begin{tabular}{|l|l|}
\hline \multicolumn{2}{|c|}{ Riesgo psicosocial } \\
\hline $\begin{array}{l}\text { De acuerdo a los } \\
\text { determinantes sociales }\end{array}$ & $\begin{array}{l}\text { Factores ambientales, } \\
\text { políticos, } \\
\text { socioeconómicos } \\
\text { y culturales. }\end{array}$ \\
\hline
\end{tabular}

\begin{tabular}{|l|l|}
\hline \multicolumn{2}{|l|}{ Riesgo biológico } \\
\hline General & $\begin{array}{l}\text { Enfermedades o } \\
\text { condiciones sistémicas } \\
\text { y uso de fármacos. }\end{array}$ \\
\hline Específico & $\begin{array}{l}\text { De acuerdo con mi riesgo } \\
\text { cariogénico }\end{array}$ \\
\hline
\end{tabular}




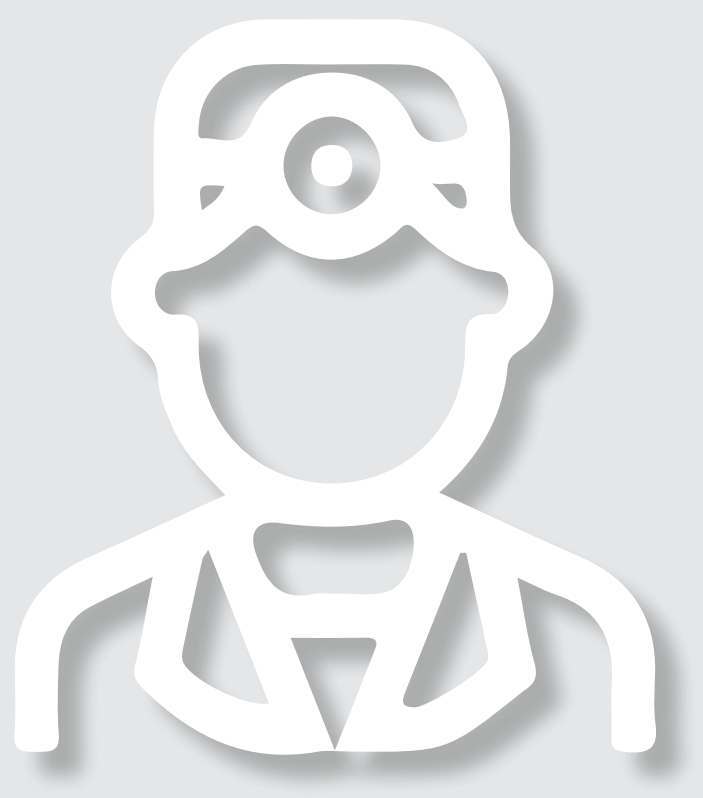




\section{Bibliográficas}

(1) http://www.minsal.cl/wp-content/uploads/2017/02/PRESENTACION-ENCAVI-2016-11.02.2017.pdf

(2) https://diprece.minsal.cl/wrdprss_minsal/wp-content/uploads/2016/12/07.12.2016_OT-CEPILLADO-DE-DIENTES-FINAL-DIGITAL.pdf

(3) https://scielo.conicyt.cl/pdf/rmc/v745n2/art12.pdf

(4) https://diprece.minsal.cl/wrdprss_minsal/wp-content/uploads/2018/02/INFORME-TECNICO-FLUOR-AGUA-POTABLE_feb-2018.pdf

(5) https://diprece.minsal.cl/wrdprss_minsal/wp-content/uploads/2014/12/Salud-Oral-Integral-ni\%C3\%B10s-y-ni\%C3\%B1as-6-a\%C3\%B10s.pdf

(6) https://diprece.minsal.cl/wrdprss_minsal/wp-content/uploads/2015/05/Tabaco-o-Salud-Bucal-Gu\%C3\%ADa-para-el-Odont\%C3\%B3logo.pdf

(7) http://www.minsal.cl/portal/url/item/7dc33df0bb34ec58e04001011e011c36.pdf

(8) http://www.crececontigo.gob.cl/tema/dientes-definitivos/

(9) http://www.minsal.cl/portal/url/item/7f2dd0d1a803c658e04001011e010fe2.pdf

(10) https://diprece.minsal.cl/wrdprss_minsal/wp-content/uploads/2015/05/Gu\%C3\%ADa-para-el-cepillado-de-dientes-en-escolares.pdf

(11) https://odontopediatria.cl/wp-content/uploads/2015/08/nueva_norma_pastas_dentales.pdf

(12) https://scielo.conicyt.cl/scielo.php?script=sci_arttext\&pid=S0718-381X2016000300021

(13) http://www.minsal.cl/wp-content/uploads/2017/12/Plan-Nacional-Salud-Bucal-2018-2030-Consulta-P\%C3\%BAblica-20_12_2017.pdf

(14) https://diprece.minsal.cl/wrdprss_minsal/wp-content/uploads/2016/03/Gu\%C3\%ADa-Cl\%C3\%ADnica-Salud-oral-integral-60.pdf

(15) https://www. salud.gob.ec/wp-content/uploads/2014/05/CARIES.pdf

(16) http://scielo.isciii.es/scielo.php?script=sci_arttext\&pid=S1699-65852008000100002

(17) https://scielo.conicyt.cl/scielo.php?script=sci_arttext\&pid=S0719-01072016000200016

(18) http://repositorio.uchile.cl/bitstream/handle/2250/123378/topicos-de-odontologia.pdf?sequence=1

(19) http://scielo.isciii.es/pdf/odonto/v30n3/original2.pdf

(20) https://diprece.minsal.cl/wrdprss_minsal/wp-content/uploads/2014/12/Urgencias-Odontol\%C3\%B3gicas-Ambulatorias.pdf

(21) https://diprece.minsal.cl/wrdprss_minsal/wp-content/uploads/2014/12/Atenci\%C3\%B3n-Odontol\%C3\%B3gica-Integral-Embarazada.pdf

(22) http://scielo.isciii.es/pdf/peri/v20n3/original4.pdf

(23) http://www.scielo.org.ve/scielo.php?script=sci_arttext\&pid=S0001-63652008000200005 
(24)https://www.revistaodontopediatria.org/publicaciones/manuales/referencia-para-procedimientos-en-odontopediatria/Manual-de-Referencia-para-Procedimientos-en-Odontopediatria-Capitulo-26.pdf

(25) $\underline{\text { http://www.scielo.edu.uy/scielo.php?script=sci_arttext\&pid=S1688-93392013000100006 }}$

(26) http://bdigital.unal.edu.co/46966/1/52889050.2014.pdf

(27) Fontana M, Zero DT. Assessing patients' caries risk. JADA 2006; 137(9):1237-9.

(28) Bratthall D, Hänsel Petersson G. Cariogram, a multifactorial risk assessment model for a multifactorial disease. Community Dent Oral Epidemiol. 2005 Aug; 33(4):256-64.

\section{Fotográficas}
a) Gentileza Universidad Autónoma de Chile
-b) Gentileza Universidad Autónoma de Chile
c) Gentileza Universidad Autónoma de Chile
d) https://www.shutterstock.com/es/image-photo/zooming-closeup-view-painful-ulcerative-lesion-1109967674?Src=kmBa41mX3ioPOplUT_010g-7-0
〜e) Gentileza Dra. Alejandra Fernández
f) https://www.shutterstock.com/es/image-photo/mouth-floor-cancer-stadium-g3-opt-633852626?src=7ES5J9YPE6MMYotFnig2c0-7-5
-g) https://www.shutterstock.com/es/image-photo/zooming-closeup-view-mouth-old-asian-732950281?src=d70bvg2eCX3UCORN3AHi-A-7-97
h) https://www.sdpt.net/par/leucoplasiapilosa.htm
-i) Gentileza Dra. Alejandra Fernández
-j) Gentileza Dra. Marcela Hernández
-k) https://scielo.conicyt.cl/scielo.php?script=sci_arttext\&pid=S0716-10182007000300007
1) https://wWw.sciencedirect.com/science/article/pii/S1130055817300060
- m) Gentileza Dr. Adrián Villena
- n) Gentileza Dr. Adrián Villena
o) Gentileza Dra. Alejandra Fernández 


\section{-> Dr. Eduardo Fernández}

Doctor en Ciencias Odontológicas por la Universidad Estatal Paulista (UNESP) de Brasil.

Cirujano dentista por la Universidad de Chile y especialista en Periodoncia por la misma casa de estudios.

Profesor titular del departamento de Odontología Restauradora de la Universidad de Chile

Investigador asociado de la Universidad Autónoma de Chile.

\section{-> Dra. Camila Alvarado}

Cirujano Dentista por la Universidad de Chile y bachiller con mención en ciencias naturales y exactas por la misma casa de estudios.

A la Universidad Autónoma de Chile y su equipo, por creer y respaldar este proyecto.

Al profesor Dr. Iván Suazo por impulsar y gestionar esta idea, a Isidora Sesnic por ejecutarla y a Camila Alvarado por realizar la mayor parte del escrito.

A mis hijos, Elisa y Eduardo, por la enorme inspiración que me motiva, y a Fran por hacer mi vida mejor. 


$$
\ddot{c}
$$



¿Cuándo debo ir al dentista? es un manual de orientación general sobre aspectos relevantes de la salud oral, tanto para adultos, como ninos, jóvenes y personas mayores, y una guía que entrega información sobre cuándo se debe acudir a un odontólogo dependiendo de la edad, las condiciones de salud y el riesgo de cada persona. El objetivo central de este manual es incentivar el cuidado de la salud oral, además de prevenir y tratar condiciones y patologias orales de forma oportuna y precoz.

¿Cuándo debo ir al dentista? es un proyecto del Centro de Comunicación de las Ciencias de la Universidad Autónoma de Chile y puede. descargarse de forma gratuita desde el sitio web ciencias.uautonoma.cl 